\title{
Research on University Core Competence
}

\author{
Yachao Xu \\ School of Education, Tianjin University \\ Tianjin, China \\ 578477978@qq.com
}

\begin{abstract}
The concept of core competitiveness of universities derives from the core competitiveness of enterprises and then explains their characteristics. The core competitiveness of universities includes discipline construction ability, teacher resources, social service ability and cultural soft power. The suggestions are as follows: optimizing the structure of the discipline, introducing talents to improve the level of teachers, inter-school alliances and strengthening the cultural construction of universities.
\end{abstract}

\section{Keywords-Universities; Core competencies; Soft power}

\section{DEFINITIONS AND CHARACTERISTICS}

The term "core competencies" comes from the corporate strategy theory proposed by Prahalad and Gary Hamel, referring to the unique skills or services that enable the company to bring special benefits to customers in the fierce market competition. It includes three conditions: First, it helps the company to further expand its business scope; second, it makes a great contribution to the company's final product; finally, it is difficult to be imitated by competitors [1]

The concept of "core competence" has been introduced into the scope of higher education management. It refers to the factors that enable a certain university to bring value to its interests and thus be in a dominant position in competition. Features are as follows:

\section{A. Accumulation}

Factors in the core competitiveness of universities need long-term accumulation. For example, the fine arts of Tsinghua University, the philosophy of Peking University, the laws of Renmin University, etc., have the core ability to gain competitive advantage in a competitive environment and have won people's recognition with their unique brand image.

\section{B. Heterogeneity}

Heterogeneity refers to the special qualities or abilities of opponents that are different from its counterparts. It exists more in the history and culture of universities. After a long time of baptism, it forms its own unique style. "Student as a teacher, behavior as a world standard" is unique to Beijing Normal University. "Allowing fair performance and improving day by day" is reminiscent of Nankai University.

\section{Dynamic}

Change is the eternal theme. Society's expectations for higher education, students for colleges and teachers for managers are constantly changing. If universities can not meet the environmental requirements and properly coordinate the core elements of the university's core competitiveness, the original core competitiveness will be lost. Therefore, the core competitiveness of universities is in a dynamic change. Universities should accurately grasp the changing factors in the environment and actively respond to new challenges.

\section{COMPONENT ANALYSIS}

This article attempts to analyze the key competencies of the university from its functions. According to the historical development sequence, the functions of universities are personnel training, scientific research and social services. The object of talent cultivation is students. Whether it is the physical teaching of tangible physical classroom or the intangible campus environment, the students' physical and mental changes have changed. In more cases, this change is positive and the student is the main body of interest of the university [2].

One of the college's products is knowledgeable people. Universities use knowledge as a carrier to shape students. Humans classify knowledge to form a clear and explicit discipline system and the quality of discipline construction affects the students' final harvest. Teachers impart the subject system and content to students. Their level and quality of discipline construction are directly related to student development. With students as the link, teachers and disciplines - students (training of talents) - the core competitiveness of universities has become an integral whole.

The purpose of scientific research is to achieve further development of theory and practice. There is no clear interest entity. The final result of scientific research will serve the society, so another interest body of the university is the society. Social service ability is an important criterion for social evaluation of universities.

At the celebration of the 100th anniversary of Tsinghua University, Hu Jintao put forward: "Higher education is the carrier of cultural heritage and the source of cultural innovation." Although the cultural heritage as the fourth major function of universities has not been widely recognized by the academic community, colleges and culture have a close relationship. The construction of cultural soft power has become the key of core competitiveness. In summary, the 
constituent elements of the core competitiveness of universities are:

\section{A. Subject construction is the foundation}

As a temple of knowledge, universities undertake the mission of imparting excellent cultural knowledge. The quality of disciplines is a direct factor in the development of universities. In the "two-class" construction, "first-rate disciplines" and "first-rate universities" are placed in the same important position and become the key to achieving the connotative development of higher education.

Judging from the relationship between discipline construction and other factors, the improvement of the discipline level will help universities attract outstanding teachers and build high-quality discipline teams. The improvement of the discipline level means that the establishment of disciplines should meet the needs of economic development and social progress. Disciplinary construction and other elements of the university's core competitiveness are closely linked.

\section{B. Teacher's level is the key}

Talent cultivation is the key to the core competitiveness of universities [3]. Talent cultivation is a process of two-way interaction between teaching and learning. As a leader of activities, teachers influence the progress of teaching activities and the depth of learning content. The university pays more attention to thinking training, emotion edification and personality development. College teachers, as trainers of cultural knowledge, organizers of research activities and practitioners of social services, directly affect the quality of talents.

Mei Yiqi believes that "university is not a building, but a master of it." Liang Qichao, Jin Yuelin and others have taught here. "Masters", as the soul and backbone of colleges and universities, influence many students with their profound thoughts, keen insight and fearless practical spirit. Harvard University regards the quality of teachers as the basis for the development of the school and believes that only teachers who have reached an international standard can be regarded as first class universities. The faculty is the embodiment of university strength, a symbol of status and the key to competition in core competitiveness.

\section{Social service is a realistic demand}

Pan Maoyuan believes: "The emergence and development of the function of colleges and universities follow a certain rule. First cultivate talents, then develop science and finally serve the society. Its importance is in line with the order of production." The emergence of social service functions is the integration of personnel training and scientific research functions. With the further development of the society, the university is no longer confined to ivory towers that deeply study knowledge and escape the constraints of the outside world. Instead, it gradually participates in social development and serves the society through the transformation of scientific research achievements.

Between 1940 and 1980, 70 percent of the Nobel Prizes came from universities. Boston Scientific Research Center, Japan's Tsukuba Technology City, America's Silicon Valley and China's Zhongguancun are all high-tech development zones based on renowned universities. The High-tech Zone has promoted the integration of production, study and research, shortened the application period of the results and provided conditions for the university to exert its social service functions. The optimized combination of teaching, research and social service functions has given rise to a model of modern universities and the coordinated development of universities and society.

\section{Cultural soft power is the core}

Forster, who once served as president of Harvard University, said: "In its essence, the task of universities is to nurture culture. The characteristics of such cultures are constantly changing or even uncontrollable. When students study, universities change individuals; when people's ideas influence the process of things, the university changes the world; when knowledge is applied to politics, the university has changed society." As a subculture of the dominant culture of society, the construction of university culture is the core of the core competitiveness of universities. University culture refers to the cultural system that is formed by the "university people" in the process of inheriting and communicating knowledge, which is related to and differentiates from the popular culture [4]. It is a collection of values, behavioral norms, beliefs and modes of thinking. Summarized as: university characteristics, or promote the light and truth (Yale University), or boast the wind of freedom (Stanford University), or by the power of God (Princeton University), or to seek truth from facts (Tianjin University) as a relentless pursuit. Cultural power is the core and driving force for forming the core competitiveness of universities [5]. Excellent university culture plays an important role in shaping the humanities. The cultural power penetrates into the cultivation of talents and the shaping of personality. It is the core element in the promotion of the core competitiveness of universities. 


\section{PROMOTION STRATEGY}

\section{A. Optimize the discipline structure and create superior disciplines}

Subject construction includes the optimization of the discipline structure and the improvement of the subject level. Both are indispensable. From the perspective of optimizing the structure of the discipline, it is necessary to rationally arrange the disciplines according to the actual, economic development requirements and social needs of the school. Strengthen the intersection and integration of disciplines, such as computers and medicine, the single development model is not conducive to the development of disciplines. [6]

Create superior disciplines and promote the coordinated development of software and hardware. In software, give full play to the research basis of the superior disciplines, enhance the level of teachers and enhance the cohesion and influence of the discipline; on the hardware, establish a sound reference room, laboratories, etc. to do the basic work for learning and scientific research.

\section{B. Introduce talents and optimize structure}

As the most basic function of the university, talent cultivation has become a non-negligible factor in competition between universities. Talent cultivation depends on highquality teachers. At present, the shortage of quality teachers is particularly evident in local universities. It is necessary for universities and colleges to increase the talent introduction. Focus on the introduction of the leaders of the superior disciplines to promote the development of the entire discipline or hire experts to help qualified young teachers [7].

Implement a targeted teacher development strategy. For academically accomplished teachers, academics should be entrusted with important tasks and actively participate in international and domestic exchanges. For young teachers, they should continue to stimulate their exuberant spirit of innovation, so that they further to the forefront of science and ultimately build a team of teachers with a reasonable structure and a clear division of labor.

\section{Enhance communication and promote local development}

Strengthening cooperation and realizing mutual complementarity of information between universities is an effective way to improve university social service capacity and enhance university core competitiveness [8]. In the process of foreign exchanges, universities should share quality education resources, accurately locate professional structures and personnel training programs. The purpose is to reserve talent for social development. The social service function began with a land grant college movement and was further established and developed by the University of Wisconsin. The media commented: "For peasants, the University of Wisconsin is as familiar as a farmhouse; for workers, it is just like a trade union." The forms of social service functions are flexible and diverse, such as the establishment of a science park and university-enterprise cooperation research center, as well as undertaking government and corporate research projects. Strengthening social services requires that colleges and universities play their autonomy and actively connect with relevant companies and departments so that society can become a university campus [9].

\section{Cultural power construction}

The foundation of cultural strength is the university's full exploration of its own culture and its active promotion of the essence of culture in universities. Take the cultural construction of the Southwest Associated University as an example: Feng Youlan believes that the Associated University has become a model of freedom and democracy in a spirit of compatibility. Someone asked Shen Congwen: "Why Southwest Union University has cultivated more talent in eight years than under the prewar combination of the talents of Peking University, Tsinghua University, and Nankai University in such difficult conditions?" His answer is "freedom." Free campus culture and spirit support the prosperity and development of a school. Campus culture can be achieved through the following methods: First, focus on building a university spirit. Cai Yuanpei advocated "compatibility and inclusiveness." Peking University became a university with a liberal mind and a fresh style of study; Stanford created a small entrepreneurial spirit to cultivate "small T-shirts" entrepreneurs. Second, strengthen the system construction, guide the teachers and students to form a good behavior through the restraint function of the system culture. In the end, no virtue will die [10]. We need both spiritual culture and material culture, such as the rational arrangement of school facilities and the campus layout of structural art. The beautiful campus environment has a strong role in cohesion and is conducive to fostering the cultivation of core competitiveness in universities.

\section{CONCLUSION}

The pace of building first-rate universities and first-rate disciplines has gradually accelerated. Higher education administrators are also actively exploring the key factors to enhance the competitiveness of the university and carrying out a series of reforms. Higher education has always been inseparable from the fundamental functions of personnel training, scientific research and social services. This requires colleges and universities to focus on subject construction and improve the level of teachers. Universities establish alliances and tap campus culture to find competitive advantages with their own characteristics. Kant believes: "University is an academic community and its quality is to independently pursue truth and academic freedom." National and government agencies should provide services for the development of higher education rather than intervention and grading. The government should create a fair and open environment and a platform for competition in universities to promote orderly competition among universities. It is the university that changes the society, not the society changes the university! This is the significance and value of the existence of the university, and it is also the basic requirement that the university's core competitiveness should be attributed to the university. 


\section{REFERENCES}

[1] Zuo Xiangguo. Analysis of the Elements of the University's Core Competitiveness[J].China Metallurgical Education,2003(5):12-16. (In Chinese)

[2] Lin Xiuying. Building the Core Competence of University Based on Customer Value[J]. China Higher Education Research.2005(12):83-84. (In Chinese)

[3] Huang Hai. An Analysis of University Core Competence Based on University Culture-University Spirit Perspective [J]. Modern Education Management.2010(12):52-54. (In Chinese)

[4] Shi Guizhou, YuXia. University Culture Enhances Core Competence in Colleges and Universities[J]. Education and Occupation.2011(33): 12-14 (In Chinese)

[5] Yu Chuanjie. The Elements and Mechanism of Core Competence in Universities[J]. Contemporary Education Science.2015(1):27-30. (In Chinese)

[6] Ding Zhexue. The Role of Disciplinary Groups in the Core Competence of Universities and Its Construction [J]. Research of Heilongjiang Higher Education.2008(1):60-61. (In Chinese)

[7] Ma Chenglin. The development strategy of local colleges and universities from the perspective of core competitiveness [J]. Heilongjiang Higher Education Research.2006(3):26-28. (In Chinese)

[8] Su Guiying. The Key to the University's Core Competence and Its Cultivation [J]. Journal of Social Science of Shanxi Universities.2007(8) 82-84. (In Chinese)

[9] Liu Baocun. Wisconsin Philosophy and University Social Service Functions [J]. Polytechnic Higher Education Research.2003(5):17-18.(In Chinese)

[10] Cheng Changchun. On University Culture and Cultivation of Universities' Soft Core Competence [N]. Journal of National Academy of Education Administration.2011(4):3-7. (In Chinese) 